\title{
Survey of Studies on Microbial Contamination of Marketed Tattoo Inks
}

\author{
Lucia Bonadonna
}

National Institute of Health, Rome, Italy

\begin{abstract}
Tattooing became a popular phenomenon during the late twentieth century. Because the act of tattooing involves repeated injection of ink through the skin, a risk of contracting infections from contaminated tattooing equipment and ink and the surrounding environment exists. Progress has been made in infection control strategies; however, contraction of bacterial and viral infections from tattooing continues to occur. The risk of acquiring a tattoo-related infection largely depends on the hygiene conditions under which the tattoo is applied. Nevertheless, even when adequate hygiene and sanitation measures are taken, the inks themselves may contain infectious microorganisms that are able to survive under hostile conditions, such as in inks. The results of the few studies on the microbiological quality of unopened and opened tattoo inks are reported. Some authors' conclusions demonstrated that the current ink sterilisation systems show a low capability to inactivate microbial contamination in tattoo inks. At the moment, European Resolution ResAP2008-1 recommends that the ink be sterile and supplied in containers that maintain the sterility of the product until application. In light of the outcomes of published studies, at the moment, preservation of the microbial quality and safety of ink seems challenging and still difficult to reach.

○ 2015 S. Karger AG, Basel
\end{abstract}

In the last few decades, tattoos have become trendy and socially acceptable, especially among adolescents and young adults, and information regarding the prevalence of tattooing among these categories of people continues to be widespread.

In recent years, infectious diseases transmitted through the practice of tattooing seem to have decreased with the step-up of professional tattoo studios and the adoption of safety measures. However, this technique is not devoid of potential adverse effects, and numerous cases of cutaneous and systemic infectious complications following tattooing are still reported $[1,2]$.

Infectious disease can be transmitted as the exogenous pigments and/or dyes penetrate the dermis and come into contact with both capillaries and lymph vessels. The risk of acquiring a tattoorelated infection largely depends on the hygiene conditions under which the tattoo is applied, and secondary infections of the tattoo lesions can also occur during the healing process.

Nevertheless, even when adequate hygiene and sanitation measures are taken, the inks themselves may contain infectious microorganisms, which together with the diluents and instruments, 
are effectively often referred to as the putative agents of tattoo-related infections [3].

Contamination may occur at various points in the ink-production process due to unsanitary manufacturing processes or use of contaminated ingredients and containers.

The actual epidemiology of tattoo-related infections is not known. In fact, it is difficult to determine the true incidence of tattoo-related infections because late, retrospective investigations are commonly conducted. Furthermore, the real incidence of infective complications after tattooing is definitely not known because most subjects choose to return to the tattoo parlour rather than consulting their own physician. In the majority of cases, it is not possible to relate the aetiological agent and the specific cause of infection; namely, it is not possible to demonstrate a cause-effect relationship. That is often due to different factors: (i) analytical investigation of the products (needles, inks, etc.) generally takes place with a delay with respect to the notification of infection; (ii) it is difficult to demonstrate an unequivocal relationship between a product and an infection, and (iii) microbiological cultural analyses of tattoo inks are complex because these products represent a very hostile environment for most microorganisms.

An Internet survey on the possible health risks associated with tattoos reported that people described skin problems (67.5\%), systemic reactions $(6.6 \%)$, fever directly after tattooing $(1.1 \%)$, and pus-filled tattoo lesions $(0.4 \%)$, which are health problems that might be associated with bacterial infections [4].

The introduction of tattoo inks into the skin has been associated with the potential entry of a great number of microorganisms, including bacteria, viruses, and fungi. Streptococcus pyogenes, methicillin-resistant Staphylococcus aureus, Pseudomonas aeruginosa, and non-tuberculous mycobacteria are often reported as bacterial aetiological agents of tattoo-related infections. In addition to local infections, increasing numbers of cases of systemic infections following professional tattoo- ing have been reported, including polymicrobial septicaemia, cases of endocarditis associated with tattooing in patients with congenital heart failure, and mycoses [5-9].

Several outbreaks of non-tuberculous mycobacterial infections in tattoo parlours, especially due to Mycobacterium chelonae, have been reported during the past few years. In these cases, the source of infection was presumed to be tap water, and the tattooist was subsequently instructed to use only sterile water for solution and dye preparation $[10,11]$.

Tattoos also represent a known risk factor for certain viral infections, such as hepatitis B and C and human immunodeficiency virus infections, although, epidemiologically, this risk factor is not considered to be statistically relevant. Both skin infection caused by the human papillomavirus and molluscum contagiosum following tattoo application have also been reported. Fungal infections due to Trichophyton rubrum and Epidermophyton floccosum have also been associated with tattoos [12-16].

Infection may also occur in the case of severe immunodeficiency, as illustrated by a lethal case of echtyma gangrenosum in a young patient with acute leukaemia [17].

As mentioned, in most cases, tattoo-related infections are caused by improper use of hygiene regimens, but sometimes pigments, diluents, and instruments can also be contaminated. Despite claims of sterility, opened and even sealed stock bottles of tattoo ink may contain microorganisms that are pathogenic for humans [18].

In the literature, very few data have been published on microorganisms present in tattoo inks and pigments in opened/unopened containers.

In 2004, a brand of a tattoo ink was removed from the market: $P$. aeruginosa and the mould Acremonium sp. were the ink contaminants [19].

A follow-up report after the introduction of the European Resolution ResAP2008-1 verified that $3 \%$ of inks from tattoo parlours were microbiologically contaminated [20]. 
Kluger and colleagues conducted bacteriological analyses on 16 tattoo inks that had previously been opened and were at that moment in use. None of the samples showed microbial or fungal growth, even if the authors did not exclude the possibility of ink contamination during the manufacturing process [21].

In total, 145 tattoo pigments (39 unopened and 106 in use) have been bacteriologically analysed. In most cases, contaminations were in a low concentration range $\left(10^{1}-10^{2} \mathrm{CFU} / \mathrm{ml}\right)$. Higher counts $\left(10^{3}-10^{8} \mathrm{CFU} / \mathrm{ml}\right)$ were recorded in four samples. Among the 31 isolated bacterial species, $64.5 \%$ were Gram-positive rods, $25.8 \%$ were Gram-positive cocci, and 9.7\% were Gram-negative rods. Pathogens were never detected [22].

Similarly, a study conducted in Denmark on 58 original tattoo inks proved microbial contamination of unopened stock bottles in $10 \%$ of the examined samples, and only one out of six in-use samples (17\%) showed microbial growth. Microbial concentrations ranged from 100 bacteria $/ \mathrm{ml}$ to 650 bacteria $/ \mathrm{ml}$, whilst yeast and moulds were never detected. Environmental bacteria and potentially pathogenic bacteria were also identified: Pseudomonas sp., Aeromonas sp., Staphylococcus sp., Enterococcus faecium, Streptococcus sanguinis, Streptococcus salivarius, and Acinetobacter sp. These three last strains were recovered from both opened and unopened ink bottles [23].

In the USA, non-tuberculous mycobacteria have often been detected in both opened and unopened bottles of ink. In most cases, non-sterile water, used as a diluent of the ink, was reported as responsible for the contamination because of the ubiquitous nature of mycobacteria [24].

Analytical controls conducted by the author and colleagues examined the microbial product safety of a total of 34 sealed and opened tattoo inks. Only three inks were not contaminated, whilst $86 \%$ of the unopened inks showed microbial growth. Different bacterial species were detected, and the concentration range (from 1 to
$>1,000 \mathrm{CFU} / \mathrm{ml}$ ) was very wide. Moulds were detected at lower concentrations than bacteria. Many species had a strictly environmental origin, but some of them were opportunistic pathogens (e.g., Neosartorya hiratsukae). As was predicted, most of the identified microbial strains were represented by highly resistant environmental microorganisms. A prevalence of endospore-forming bacteria (e.g., different species of Bacillus); anaerobic, spore-forming bacteria; and aerobic, spore-forming bacteria, such as Alicyclobacillus acidocaldarius, were cultured from the sealed inks. Most of the strains isolated from the opened tattoo inks belonged instead to the cutaneous human microbiome (e.g., Staphylococcus sp.) [25].

The Food and Drug Administration has published advice related to recalling lots of tattoo inks and tattoo needles due to pathogenic bacterial contamination. From the tattoo kits (inks and needles), a variety of potentially pathogenic organisms were isolated and identified, including Gram-negative bacteria and Gram-positive rods and cocci. In particular, Bacillus sp., Sphingomonas paucimobilis, Micrococcus luteus, Corynebacterium sp., and species belonging to the genus Clostridium were identified [26].

The sterility of manufactured inks has recently been questioned [27]. In national and European frameworks, the lack of specific regulation requiring ink sterility control has disallowed the assessment of the infectious risk to public health. In contrast, in the USA, under the Federal Food, Drug, and Cosmetic Act, tattoo inks are considered to be cosmetics, whereas the pigments used in the inks are colour additives that require premarketing approval. This law requires that cosmetics and their ingredients not be adulterated or misbranded, which means that they cannot contain poisonous or deleterious substances or unapproved colour additives, be manufactured or held under unsanitary conditions, or be falsely labelled. Furthermore, cosmetic manufacturers are supposed to ensure the safety of a product before marketing it. 
Table 1. Notifications of microbial tattoo ink contamination reported by RAPEX

\begin{tabular}{lll}
\hline Year & Notifying country & Risk \\
\hline 2006 & France & Moraxella, Staphylococcus warneri \\
2007 & The Netherlands & P. aeruginosa $1,500 \mathrm{CFU} / \mathrm{ml}$ \\
2007 & Germany & Mesophiles, total bacteria $7.71 \times 10^{5} \mathrm{CFU} / \mathrm{g}$ \\
2008 & Germany & Mesophiles, total bacteria $8.1 \times 10^{7} \mathrm{CFU} / \mathrm{g}$, P. aeruginosa \\
& & Mesophiles, total bacteria $3.6 \times 10^{6} \mathrm{CFU} / \mathrm{g}$, P. aeruginosa \\
& & $1.1 \times 10^{6} \mathrm{CFU} / \mathrm{g}$, yeast $9 \times 10^{5} \mathrm{CFU} / \mathrm{g}$ \\
2009 & The Netherlands & Pseudomonas: 41 contaminated inks \\
2010 & Italy & General microbial risk \\
\hline
\end{tabular}

In fact, tattooing is subject to little control regarding both ink production/sterilisation and tattooing practices in order to ensure the consumers' health. In table 1, the advice of RAPEX, the European rapid alert system, on the microbial risk associated with tattooing products is reported. The few notifications are probably due to scarce microbiological controls executed by European laboratories [28].

In the last decade, two recommendations have been made by the Council of Europe regarding the safety of tattooing. ResAP2003-2 [29] established that tattoo products had to be manufactured in sterile single-use containers without preservatives, while ResAP2008-1 [30] subsequently legalised the use of preservatives and multi-use containers, without providing appropriate details on sterilisation and preservation modalities. Furthermore, national regulations can greatly vary. According to ResAP2008-1, tattoo inks should be sterilised before marketing. Both beta and gamma radiations are generally suitable for sterilisation. This sterilisation technology is widely used in many countries and enables products, including their packaging, to be sterilised without altering their organoleptic, physical, and chemical characteristics. The main difference between beta and gamma radiations lies in their material penetration and their dose rates (beta rays: high dose rate and limited penetration depth; gamma rays: high penetration capability and relatively low dose rate). Both types of ionising radiation should destroy the DNA of microorganisms, thus inactivating them. Radiation resistance varies widely among different microorganisms, and this is related to differences in their chemical and physical structures as well as in their ability to recover from radiation injury. The radiation technology is considered safe, reliable, and highly effective. As recommended by the International Organization for Standardization [31], the sterilisation dose must be set for each type of product depending on its bioburden, and the manufacturer has the responsibility of identifying the sterilisation dose.

Nevertheless, it is recognised that the sterility of an individual item in a population of sterilised products cannot be ensured in the absolute sense.

According to the Pharmacopeia [32], for products to be considered sterilised, the sterility assurance level (SAL) is accepted. Since achievement of the absolute state of sterility cannot be demonstrated, the sterility of a product can be defined only in terms of probability. Thus, the SAL is the probability that not more than one viable microorganism is present in an amount of one million sterilised items of the final product $\left(\mathrm{SAL} 10^{-6}\right)$. The probability of microbial survival is a function of the number and species of microorganisms present in the product (bioburden), the sterilisation process lethality, and the type of product submitted to sterilisation treatment. 
The sterility process needs well-planned quality control to ensure that irradiation reaches the inner part of the product, killing microorganisms and preventing their ability to recover from radiation injury. It is evident, therefore, that understanding the specific nature of radiation is important in order to properly use this sterilisation technique in practice.

Most bacterial isolates in the mentioned studies had particular resistance capability (e.g., Bacil- lus sp.), which is also true for moulds able to survive under unfavourable environmental conditions.

In light of the data reported in the literature and in view of a revision of the European principles on tattooing, in order to obtain reliable results, it is important to highlight that microbiological quality control should contemplate the use of appropriate microbial parameters and valid analytical methods.

\section{References}

1 Kazandjieva J, Tsankov N: Tattoos: dermatological complications. Clin Dermatol 2007;25:375-382.

-2 Kaatz M, Elsner P, Bauer A: Body-modifying concepts and dermatologic problems: tattooing and piercing. Clin Dermatol 2008;26:35-44.

3 Kennedy BS, Bedard B, Younge M, Tuttle D, Ammerman E, Ricci J, Doniger AS, Escuyer VE, Mitchell K, NobleWang JA, O'Connell HA, Lanier WA, Katz LM, Betts RF, Mercurio MG, Scott GA, Lewis MA, Goldgeie MH: Outbreak of Mycobacterium chelonae infection associated with tattoo ink. N Engl J Med 2012;367:1020-1024.

-4 Klügl I, Hiller KA, Landthaler M, Bäumler W: Incidence of health problems associated with tattooed skin: a nationwide survey in German-speaking countries. Dermatology 2010;221:43-50.

5 Korman TM, Grayson ML, Turnidge JD: Polymicrobial septicaemia with Pseudomonas aeruginosa and Streptococcus pyogenes following traditional tattooing. J Infect 1997;35:203.

6 Mathur DR, Sahoo A: Pseudomonas septicaemia following tribal tattoo marks. Trop Geogr Med 1984;36:301302.

7 Charnack C: Tattooing dyes and pigments contaminated with bacteria. Tidsskr Nor Laegeforen 2004;124:2278.

8 Kluger N, Muller C, Gral N: Atypical mycobacteria infection following tattooing: review of an outbreak in 8 patients in a French tattoo parlor. Arch Dermatol 2008;144:941-942.

9 Wolf R, Wolf DA: Tattooed butterfly as a vector of atypical Mycobacteria. J Am Acad Dermatol 2003;48:S73-S74.
10 Falsey RR, Kinzer MH, Hurst S, Kalus A, Pottinger PS, Duchin JS, Zhang J, NobleWang J, Shinohara MM: Cutaneous inoculation of nontuberculous mycobacteria during professional tattooing: a case series and epidemiologic study. Clin Infect Dis 2013;57:e143-e147.

-11 Kay MK, Perti TR, Duchin JS: Tattooassociated Mycobacterium haemophilum skin infection in immunocompetent adult, 2009. Emerg Infect Dis 2011; 17:1734-1736

$\checkmark 12$ Rosario Pac M, Arnedo A, Montaner MD, Prieto P, García J, Izuel M, León P, López JA, Echevarría JM: Epidemic outbreak of hepatitis B from the tattoo in gypsy families. Rev Esp Salud Publica 1996;70:63-69.

$>13$ Limentani AE, Elliott LM, Noah ND, Lamborn JK: An outbreak of hepatitis B from tattooing. Lancet 1979;2:86-88.

14 Miller DM, Brodell RT: Verruca restricted to the areas of black dye within a tattoo. Arch Dermatol 1994;130:1453-1454.

15 Pérez Gala S, Alonso Pérez A, Ríos Buceta L, Aragüés Montañés M, García Díez A: Molluscum contagiosum on a multicoloured tattoo. J Eur Acad Dermatol Venereol 2006;20:221-222.

16 Salmaso F, Gnecchi L, Gianotti R, Veraldi S: Molluscum contagiosum on a tattoo. Acta Derm Venereol 2001;81:146-147.

$>17$ Tendas A, Niscola P, Barbati R, Abruzzese E, Cuppelli L, Giovannini M, Scaramucci L, Fratoni S, Ales M, Neri B, Morino L, Dentamaro T, De Fabritiis P: Tattoo related pyoderma/ectyma gangrenous as presenting feature of relapsed acute myeloid leukaemia: an exceptionally rare observation. Injury 2011;42:546-547.
18 Le Blanc PM, Hollinger KA, Klontz KC: Tattoo ink - related infections - awareness, diagnosis, reporting, and prevention. N Engl J Med 2012;367:985-987.

19 Harp BP: FDA: tattoos and permanent makeup. 2009. http://learningcenter. nsta.org/products/symposia_seminars/ fall09/fda/files/WS4-12-17-09.ppt (accessed September 29, 2014).

20 Swiss Confederation: Conformity of tattooing- and permanent make-upcolours not satisfied. 2006. http://ctltattoo.net/FOPH-Report_tattoocolours_control-campaign.pdf (accessed September 29, 2014).

21 Kluger N, Terru D, Godreuil S: Bacteriological and fungal survey of commercial tattoo inks used in daily practice in a tattoo parlor. J Eur Acad Dermatol Venereol 2011;25:1230-1231.

22 Baumgartner A, Gautsch S: Hygienicmicrobiological quality of tattoo- and permanent make-up colours. J Verbrauch Lebensmitt 2011;6:319-325.

23 Høgsberg T, Saunte DM, FrimodtMøller N, Serup J: Microbial status and product labelling of 58 original tattoo inks. J Eur Acad Dermatol Venereol 2013;27:73-80

24 Kennedy BS, Bedard B, Younge M, Tuttle D, Ammerman E, Ricci J, Doniger AS, Escuyer VE, Mitchell K, NobleWang JA, O'Connell HA, Lanier WA, Katz LM, Betts RF, Mercurio MG, Scott GA, Lewis MA, Goldgeier MH: Outbreak of Mycobacterium chelonae infection associated with tattoo ink. N Engl J Med 2012;367:1020-1024. 
25 Bonadonna L, Briancesco R, Coccia A, Fonda A, Meloni P, Semproni M: Microbiological quality and product labelling of tattoo inks. Proceedings 1st European Congress on Tattoo and Pigment Research, Copenhagen, November 13-14, 2013.

26 U.S. Food and Drug Administration: Voluntary nationwide recall of tattoo ink, tattoo needles, tattoo kits due to microbial contamination. 2014. http:// www.fda.gov/Safety/Recalls/ucm 405474 . htm (accessed September 29, 2014).

27 Centers for Disease Control and Prevention (CDC): Tattoo-associated nontuberculous mycobacterial skin infections - multiple states, 2001-2012. Morb Mortal Wkly Rep 2012;61:653656
28 European Commission: Health and consumers. RAPEX notification. 2014. http://ec.europa.eu/consumers/archive/ safety/rapex/index_en.htm (accessed September 29, 2014).

29 Council of Europe, Committee of Ministers: Resolution ResAP (2003)2 on Tattoos and Permanent Make-Up. Strasbourg, France, Council of Europe, 2003.
30 Council of Europe, Committee of Ministers: Resolution ResAP (2008)1 on Requirements and Criteria for the Safety of Tattoos and Permanent Make-Up (Superseding Resolution ResAP(2003)2 on Tattoos and Permanent Make-Up). Strasbourg, France, Council of Europe, 2008.

31 ISO 11137-1:2006/Amd1:2013. Sterilization of health care products - Radiation - Part 1: Requirements for development, validation and routine control of a sterilization process for medical devices. Geneva, Switzerland, International Organization for Standardization, 2013.

32 European Directorate for the Quality of Medicines, Council of Europe: European Pharmacopoeia, ed 8. Strasbourg, France, Council of Europe, 2014. 